\title{
Partnership Interacts with the Association between Leisure-Time Physical Activity and Positive Affect
}

\author{
Kourosh Bador ${ }^{1}$, Nima Bador ${ }^{1}$, Nóra Kerekes ${ }^{2}$ \\ ${ }^{1}$ Agera Sweden ACT AB, Borås, Sweden \\ ${ }^{2}$ Department of Health Sciences, University West, Trollhättan, Sweden \\ Email: kourosh@ageraboras.se
}

Received 14 February 2016; accepted 31 May 2016; published 3 June 2016

Copyright (C) 2016 by authors and Scientific Research Publishing Inc.

This work is licensed under the Creative Commons Attribution International License (CC BY). http://creativecommons.org/licenses/by/4.0/

(c) (i) Open Access

\section{Abstract}

Background: Subjective well-being is a central concept of positive psychology, and is directly coupled with a high level of positive affect and a low level of negative affect. Positive affect is associated with enthusiasm, activity, hope and inspiration, while negative affect is associated with emotions such as anger, contempt, guilt, shame, fear, anxiety, depression, and stress. Physical activity is crucial for both physical and mental health and is positively associated with well-being. Gender and social factors (e.g., parenthood or partnership) have complex relations with well-being and affect. In the present study we aimed to 1) examine the association between leisure-time physical activity and affect and 2) investigate whether or not social factors interact with this association. Method: The study included information from 155 Swedish university students: 64 men (mean age 23 years) and 91 women (mean age 27 years). Students were asked to estimate their usual engagement in physical activity during their leisure-time by responding to the Godin Leisure-Time Exercise Questionnaire. They also reported the level of positive and negative emotions experienced during past weeks by completing the Positive Affect and Negative Affect Schedule instrument. Results: In the Swedish student population leisure-time physical activity correlated only with positive and not with negative affect. Students' gender, age or whether or not they had children did not influence this association. However, this correlation differed significantly between those who lived with a partner and those who were single. Conclusion: Leisure-time physical activity is positively correlated with an overall subjective well-being, and this correlation is modified by the social factor of partnership.

\section{Keywords}

Leisure-Time Physical Activity, Positive Affect, Partnership, Students, Well-Being 


\section{Introduction}

Most major psychological dilemmas and human problems involve-in one way or another-emotion and affect. Affect is generally considered to be a broader construction than emotion and is often defined in terms of its characteristic tone or intensity (Batson et al., 1994). Watson and Tellegen (1985) were the first to reveal a basic two-factor structure of affect: pleasantness versus unpleasantness is one factor, and degree of arousal or activation the other. The characteristic tone, pleasantness or unpleasantness, is coded as Positive Affect (PA) or Negative Affect (NA). While Watson and Tellegen (1985) argued that PA and NA are two separate dimensions and not each other's opposites, more recent studies have rejected the hypothesis of the complete independence between PA and NA (Crawford \& Henry, 2004). While PA is associated with enthusiasm, activity, hope, and inspiration, NA is associated with emotions such as anger, contempt, guilt, shame, fear, anxiety, depression, and stress (Watson et al., 1988; Kerr \& Kuk, 2001; Thøgersen-Ntoumani et al., 2005). High PA combined with low NA contributes to greater subjective experience of well-being (Jayawickreme et al., 2012).

In positive psychology the relevant concept is subjective well-being, which is characterized by a positive mood, energy, efficiency, and the recognition of impediments as challenges rather than threats (Greenglass \& Fiksenbaum, 2009; Jayawickreme et al., 2012), and which is directly related to PA, social support, coping ability, and motivation (Jayawickreme et al., 2012; Seligman \& Csikszentmihalyi, 2000; Seligman et al., 2005). In this approach PA promotes the ability to set goals, to have a strong belief in one's own abilities, and to use all available resources for self-development and to act in challenging situations.

Positive psychology also explored the effect of physical activity on affect. Regular physical exercise has been shown to be associated with high PA and low NA (Barnett, 2013; Hogan et al., 2013; Norlander et al., 2002). People who engage in physical exercise are also on average more satisfied and happy with their lives than those who do not (Stubbe et al., 2007). Frequent physical exercise has been associated with good mental health, the prevention of depression and anxiety, and the promotion and maintenance of positive self-esteem and sense of well-being in teenagers (Rees \& Sabia, 2010; Rothon et al., 2010) and in adults (Arciero \& Ormsbee, 2009; Baldwin, 2010; Hawker, 2012). The relation between well-being and physical activity seems to be somewhat more straightforward than the relationship between well-being and parenthood or partnership. In recent decades many studies have investigated whether parenthood is associated with decreased or increased subjective well-being. Conflicting results have shown that the relationship between parenthood and well-being is highly complex, and includes the emergence of strongly increased emotions, both positive and negative (Nelson et al., 2014). It has also been suggested that active parenting, taking care of a child, is a source of greater positive emotions for parents than other activities they perform (Nelson et al., 2014). Similarly, the association between relationship status and well-being has been researched and it has been repeatedly found that those who are single usually report lower levels of well-being (Diener et al., 2000; Haring-Hidore et al., 1985), while individuals living with a partner generally have a better quality of life (Vuillemin et al., 2005). However, those singles whose personality profile is characterized by high avoidance goals still reported the same level of well-being and life satisfaction as people involved in a relationship (Girme et al., 2015), an observation which calls for caution when generalizing the positive correlation between happiness and being involved in a romantic partnership.

While we know that social and environmental factors such as parenting, involvement in a romantic partnership, or the amount of physical activity individuals engage in all have a strong effect on well-being (BellowsRiecken \& Rhodes, 2008), to our knowledge no research has yet identified how parenthood or partnership status may modify the association between physical exercise and affect. In the present study we examine the relationship between leisure-time physical activity and affect in a Swedish student population and investigate whether or not gender, age, parenthood or partnership status modifies the association. Our hypothesis was that social factors like being a parent or being involved in a romantic partnership considerably modify the previously reported positive association between physical activity and PA.

\section{Method}

\subsection{Participants}

The participants in this study were students at University West, Sweden. Participation was voluntary and anonymous. Students from three classes (two classes from the psychology program and one from the land surveying 
program) were informed about the project's aim and procedure. Of the 89 psychology students and 90 engineering students, 82 and 73, respectively, agreed to participate (87\% compliance) by completing two self-rating instruments (PANAS and LTPQ). Those who chose not to participate left the classrooms. 155 questionnaires were distributed and collected. One psychology student did not complete one instrument (PANAS) resulting in a final study population of 154 . Gender distribution within the sample was $41 \%$ men $(n=64)$ and $59 \%$ women $(n=91)$. The sample's age range was 18 to 52 years, not following a normal distribution, with a mean age of 25 and median age of 23 (for men $M=23.11 S D=5.10$; for women $M=26.74 S D=8.30$ ).

121 participants did not have children (57 men and 64 women) and 33 participants did (6 men and 27 women). 72 participants were single (35 men and 37 women) and 82 were in a partnership (28 men and 54 women). Partnerships included marriage, living together as a couple, or living apart as a couple. This latter partnership is a common, socially accepted partnership form in Sweden, described as a stable romantic relationship but without cohabitation.

\subsection{Instruments}

The questionnaire began with a few demographic questions about the participants: gender, age, marital/partnership status, height, weight, number of children, and current course in school.

Affect was measured using the Positive Affect and Negative Affect Schedule (PANAS) instrument (Watson et al., 1988), an instrument that allows participants to rate on a five-point Likert scale to what extent they had experienced the listed 20 feelings within the last few weeks. The Swedish version of PANAS has been used in several studies in recent years (Garcia et al., 2012; Nima et al., 2013; Garcia \& Archer, 2014). The PA scale, consisting of 10 adjectives, reflects how much a person experiences and feels energy, strength, and inspiration. The PA scale had a Cronbach's $\alpha$ of 0.86 in the present study. The NA scale, also consisting of 10 feelings, describes undesirable inner experiences such as guilt, shame, contempt, disgust, and nervousness. This scale had a Cronbach's $\alpha$ of 0.79 in our study.

Physical exercise was measured using the Godin Leisure-Time Exercise Questionnaire (LTEQ), which is a 3 +1 -item scale for assessing the frequency and intensity of physical exercise during a typical seven-day period. The first three items measure how often the respondent engages in different intensities of leisure-time physical activities. The participants are given examples of 1) mild (minimum effort, no sweating as in playing golf), 2) moderate (not tiring, light sweating as in brisk walking), and 3) strenuous (raising the heartbeat, as in jogging) workouts, and are asked to report how many times on average they engaged in various types of exercise that lasted longer than 15 minutes during their leisure time. The scale allows the calculation of an overall score of LTEQ through summing the scores computed according to the following formula: multiply the number of strenuous workouts by 9 , the number of moderate trainings by 6 , and the number of mild exercise sessions by 3 . The fourth item of LTEQ is an independent question, which measures the frequency of physical activity as a categorical value; it was not used in the present study.

\subsection{Statistical Analyses}

The collected data of PANAS and LTEQ showed a close to normal distribution, therefore parametric analyses were conducted. PA and NA scores were used as dependent variables in separate linear regression models, with LTEQ as the independent variable. If the model was significant, age, gender, parenthood, and partnership status were entered together with their LTEQ interaction term, one (variable + variable * LTEQ) at a time, to find out if these variables interacted with the PA and NA vs LTEQ correlation. As a third step, all variables with a significant LTEQ interaction were entered into a multivariable regression model. Beta estimates $(\beta)$, p-values and $\mathrm{R}^{2}$ are presented for each model. All the tests were two-tailed and conducted at the $5 \%$ significance level. The analyses were conducted with SAS 9.4.

\subsection{Ethical Considerations}

Participation was voluntary and anonymous. The survey's cover page informed the participants about the questionnaire's content and aim and stressed the freedom to choose whether or not to participate in the anonymous data collection. According to Swedish law (2003: 460, §2) on the ethics of research involving humans, the present study required no specific ethical approval. 


\section{Result}

In the Swedish university student population studied, the level of leisure-time physical activity was positively and significantly correlated with reported PA in the linear regression model $\left(\beta\right.$ (LTEQ) $=0.068, R^{2}=0.082, p=$ $0.0003)$. The association between physical activity and NA was very low $\left(\beta(\right.$ LTEQ $)=-0.016, R^{2}=0.005, p=$ 0.39), and therefore was not used further in interaction analyses.

Interaction between partnership and LTEQ was significant when predicting PA $\left(\beta(\mathrm{LTEQ})=0.086, R^{2}=0.114\right.$, $p=0.0300)$. For those who lived alone a significantly stronger correlation $(\beta(\mathrm{LTEQ})=0.105, p<0.001)$ was found between leisure-time physical activity and PA than for those who lived in a partnership $(\beta(\mathrm{LTEQ})=0.019$, $p=0.53$ ) (Table 1 and Figure 1$)$. However, there were no interactions of gender $(\beta(\mathrm{LTEQ})=0.008, p=0.83)$, age $(\beta(\mathrm{LTEQ})=-0.003, p=0.22)$ or parenthood $(\beta(\mathrm{LTEQ})=-0.058, p=0.20)$ with leisure-time physical activity and PA.

The final model, which shows a significant interaction of partnership with the association between leisure-time physical activity and PA, is presented in Table 1 and Figure 1.

\section{Discussion}

The main aim of the present study was to examine the relationship between leisure-time physical activity and affect in a Swedish student population and to investigate if biological factors, like gender and age, or sociological variables, such as parenthood and partnership, would modify the association.

Table 1. The final model of partnership, leisure-time physical activity and positive affect using multivariable linear regression analysis.

\begin{tabular}{cccc}
\hline & $\beta$ & $S E$ & $p$ \\
\hline Intercept & 29.424 & 1.503 & $<0.0001$ \\
Partnership & 4.774 & 2.066 & 0.0222 \\
LTEQ & 0.105 & 0.024 & $<0.0001$ \\
Partnership * LTEQ & -0.086 & 0.039 & 0.0300
\end{tabular}

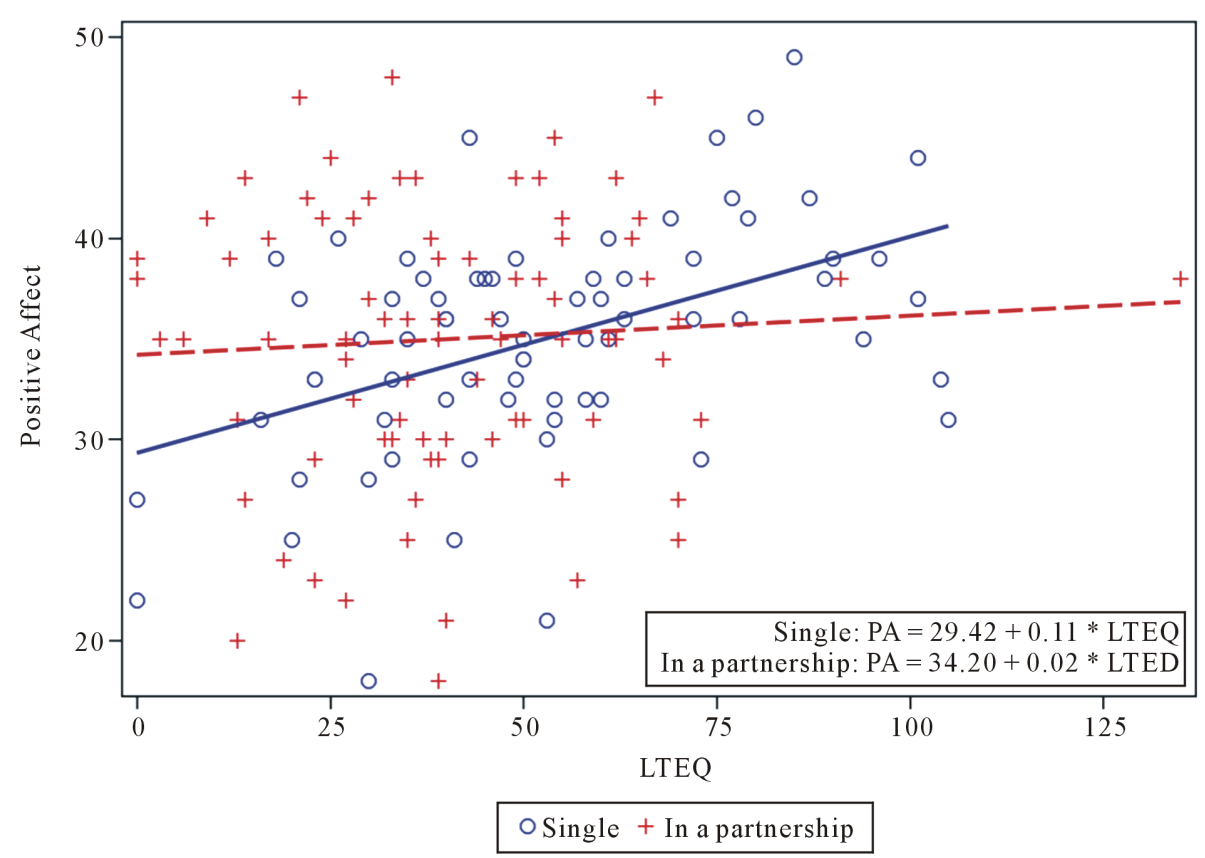

Figure 1. The interaction between partnership and leisure-time physical activity (LTEQ) and positive affect. 


\subsection{Leisure-Time Physical Activity Is Positively Correlated with PA}

Our result describing a positive and significant correlation between leisure-time physical activity and PA is in accord with previous findings (for example, Arciero \& Ormsbee, 2009; Garcia \& Archer, 2014; Kerr \& Kuk, 2001). One possible explanation of this association was that those who engage in structured and planned physical exercise feel better and achieve a better mood than those who do not (Desharnais et al., 1993). But causality can work both ways, so those who experience PA may be more able to plan, organize, and maintain physical exercise than those with more NA (Garcia \& Archer, 2014). Research in positive psychology has found that those with high PA experience subjective well-being, have more energy, and are more efficient in carrying out their commitments because they experience demands as challenges rather than as negative stressors (Greenglass \& Fiksenbaum, 2009; Jayawickreme et al., 2012). The present study cannot explain any causality, but it reinforces that more leisure-time physical activity is coupled with an experience of more PA, and higher PA in a person results in them being better able to maintain a commitment to exercise. The "circle of exercise-approach behavior” (Garcia et al., 2012) describes this two-way interaction between PA, physical activity and even well-being, showing that positive affectivity contributes to well-being and may result in increased engagement in exercise, and at the same time involvement in physical activity may lead to self-concepts enhanced by positive affect like pride and contentedness. Stubbe and colleagues (2007), using a genetically sensitive population to study causality relation in the association between leisure-time physical activity and well-being, suggested that this relation is non-causal but is mediated mostly by common genetic factors behind exercise behavior and life-satisfaction or happiness.

At the end of the1990s there were different views on the relationship between exercise and affect (see Gauvin \& Spence, 1996). Some argued that exercise could be used systematically to regulate an individual's experience of negative emotions such as anger, depression, or anxiety (North et al., 1990). Our results indicated no significant association between leisure-time physical activity and NA and therefore supports those who claimed that physical training is coupled mainly with an experience of positive emotions such as strength, inspiration, enthusiasm, and hope (for example, Desharnais et al., 1993; Reed \& Ones, 2006).

\subsection{The Effects of Biological and Social Factors on the Experience of PA in Association with Physical Activity}

In our study none of the biological factors, gender or age, were found to interact with the association between leisure-time physical activity and PA. Considering gender, it has been previously suggested that men who exercise benefit from this activity more than women do, in that they are happier and more satisfied with their lives than women who exercise (Huang \& Humphreys, 2012). An explanation could be found in the well-established gender differences of personality. It has been shown that women score more than men on the neuroticism personality aspect measured by the Big Five (Costa Jr. et al., 2001; Weisberg et al., 2011). Because neuroticism predisposes a person to NA, women are therefore in general more prone to NA than men and may have greater difficulty experiencing the same positive effect of physical exercise as men. Hayes and colleagues (1999) speculated that men have higher levels of physical self-perception, and through the mediating effect of physical self-worth they can achieve higher levels of self-esteem than women can, and that self-esteem has a component of positive (or negative) emotion that contributes to affect (Rosenberg et al., 1995). However, results from other studies did not corroborate any gender-specific association between physical activity and affect (for example, Garcia et al., 2012; Stubbe et al., 2007), and likewise in our population, gender did not modify the positive correlation between leisure-time physical activity and PA. This would suggest that, at least in student and young adult populations, both men and women use physical activity to maintain an overall subjective well-being. Age, the other biological variable in our study, also did not interact with physical activity in its association with PA. These findings support previous conclusions stating that the association between PA and physical activity is independent of gender and age (Garcia et al., 2012; Stubbe et al., 2007), while not opposing the importance of age, for example in exercise compliance (Garcia \& Archer, 2014).

Today, it is know that social factors have a strong effect on human emotion and well-being and an indirect impact on mental health. Therefore our hypothesis was that social factors, like parenthood or partnership, would modify the association of leisure-time physical activity and affect. According to our knowledge, this aspect has not been previously studied. When we divided our study population according to parenthood and partnership, the positive correlation between leisure-time physical activity and PA weakened in those who had children and 
in those who lived in a partnership, reaching the level of significance only in the latter case. The correlation between physical activity and PA was significantly stronger in those who were single than in those living in a partnership. The relatively low number of parents (21\%) may have contributed to the non-significant interaction effect of this variable; however, the close to equal distribution of singles (47\%) and those in a relationship (53\%) made it feasible to discern the effect of partnership on the association between physical activity and PA. A possible explanation of the significant interaction of partnership is that people living in a relationship have activities other than physical exercise to boost their PA, because they interpret the world from the perspective of their familial achievements and future plans. Conversely, for those who live as singles, physical activity may have an important role in providing a source of interest, excitement, activity, and enthusiasm, thereby increasing positive affectivity and life satisfaction.

\section{Limitations of the Study}

One obvious limitation of the present study was that the participants were university students. The findings should therefore be carefully considered before being generalized or applied to other populations with different backgrounds. The relatively small scale of the study limited the reliability of repeated statistical analyses. One of the most important limitations of the present study is that all information was collected using self-rating instruments. While the method of self-reporting is common, cheap and appropriate, it is important to acknowledge that it is also burdened with potential bias, such as eventual recall bias, or the answers could be distorted by social desirability. Given that both the measure of affect and the measure of leisure-time physical activity intensity came from the same source, we have an important problem to consider. For example, people with greater PA may exaggerate their levels of activity, or vice versa.

\section{Conclusion}

Living in a romantic partnership significantly weakens the positive association between leisure-time physical activity and positive affect. Further research on the competing effects of social environmental factors on mood, emotions, and affect is needed.

\section{References}

Arciero, P. J., \& Ormsbee, M. J. (2009). Relationship of Blood Pressure, Behavioral Mood State, and Physical Activity Following Caffeine Ingestion in Younger and Older Women. Applied Physiology, Nutrition and Metabolism, 34, 754-762. http://dx.doi.org/10.1139/H09-068

Baldwin, R. C. (2010). Preventing Late-Life Depression: A Clinical Up-Date. International Psychogeriatrics, 1, 1-9.

Barnett, F. (2013). The Effect of Exercise on Affective and Self-Efficacy Responses in Older and Younger Women. Journal of Physical Activity \& Health, 10, 97-105.

Batson, C. D., Shaw, L. L., \& Oleson, K. C. (1994). I Feel, Therefore I Am—I Think. In P. Ekman, \& R. J. Davison (Eds.), The Nature of Emotion: Fundamental Questions (pp. 379-385). New York: Oxford University Press.

Bellows-Riecken, K. H., \& Rhodes, R. E. (2008). A Birth of Inactivity? A Review of Physical Activity and Parenthood. Preventive Medicine, 46, 99-110. http://dx.doi.org/10.1016/j.ypmed.2007.08.003

Costa Jr., P., Terracciano, A., \& McCrae, R. R. (2001). Gender Differences in Personality Traits across Cultures: Robust and Surprising Findings. Journal of Personality and Social Psychology, 81, 322-331. http://dx.doi.org/10.1037/0022-3514.81.2.322

Crawford, J. R., \& Henry, J. D. (2004). The Positive and Negative Affect Schedule (PANAS): Construct Validity, Measurement Properties and Normative Data in a Large Non-Clinical Sample. British Journal of Clinical Psychology, 43, 245. http://dx.doi.org/10.1348/0144665031752934

Desharnais, R., Jobin, J., Cote, C., Levesque, L., \& Godin, G. (1993). Aerobic Exercise and the Placebo Effect: A Controlled Study. Psychosomatic Medicine, 55, 149-154. http://dx.doi.org/10.1097/00006842-199303000-00003

Diener, E., Gohm, C. L., Suh, E., \& Oishi, S. (2000). Similarity of the Relations between Marital Status and Subjective Well-Being across Cultures. Journal of Cross-Cultural Psychology, 31, 419-436.

http://dx.doi.org/10.1177/0022022100031004001

Garcia, D., \& Archer, T. (2014) Positive Affect and Age as Predictors of Exercise Compliance. PeerJ, 2, e694. http://dx.doi.org/10.7717/peerj.694 
Garcia, D., Archer, T., Moradi, S., \& Andersson-Arntén, A. C. (2012) Exercise Frequency, High Activation Positive Affect, and Psychological Well-Being: Beyond Age, Gender, and Occupation. Psychology, 3, 328-336. http://dx.doi.org/10.4236/psych.2012.34047

Gauvin, L., \& Spence, J. (1996) Physical Activity and Psychological Well-being: Knowledge Base, Current Issues, and Caveats. Nutrition Reviews, 54, S53-S65.

Girme, Y. U., Overall, N. C., Faingataa, S., \& Sibley, C. G. (2015). Happily Single. The Link between Relationship Status and Well-Being Depends on Avoidance and Approach Social Goals. Social Psychological and Personality Science, Published online before print.

Greenglass, E. R., \& Fiksenbaum, L. (2009). Proactive Coping, Positive Affect, and Well-Being: Testing for Mediation Using Path Analysis. European Psychologist, 14, 29-39. http://dx.doi.org/10.1027/1016-9040.14.1.29

Haring-Hidore, M., Stock, W. A., Okun, M. A., \& Witter, R. A. (1985). Marital Status and Subjective Well-Being: A Research Synthesis. Journal of Marriage and Family, 47, 947-953. http://dx.doi.org/10.2307/352338

Hawker, C. L. (2012). Physical Activity and Mental Well-Being in Student Nurses. Nurse Education Today, 32, 325-331. http://dx.doi.org/10.1016/i.nedt.2011.07.013

Hayes, S. D., Crocker, P. R. E., \& Kowalski, K. C. (1999). Gender Differences in Physical Self-Perceptions, Global Self-Esteem and Physical Activity: Evaluation of the Physical Self-Perception Profile Model. Journal of Sport Behavior, 22, 1-14.

Hogan, C. L., Mata, J., \& Carstensen, L. L. (2013). Exercise Holds Immediate Benefits for Affect and Cognition in Younger and Older Adults. Psychology and Aging, 28, 587-594. http://dx.doi.org/10.1037/a0032634

Huang, H., \& Humphreys, B. R. (2012). Sports Participation and Happiness: Evidence from US Microdata. Journal of Economic Psychology, 33, 776-793. http://dx.doi.org/10.1016/j.joep.2012.02.007

Jayawickreme, E., Forgeard, M. J. C., \& Seligman, M. E. P. (2012). The Engine of Well-Being. Review of General Psychology, 16, 327-342. http://dx.doi.org/10.1037/a0027990

Kerr, J. H., \& Kuk, G. (2001). The Effects of Low and High Intensity Exercise on Emotions, Stress and Effort. Psychology of Sport and Exercise, 2, 173-186. http://dx.doi.org/10.1016/S1469-0292(00)00021-2

Nelson, S. K., Kushlev, K., \& Lyubomirsky, S. (2014). The Pains and Pleasures of Parenting: When, Why, and How Is Parenthood Associated with More or Less Well-Being? Psychological Bulletin, 140, 846-895. http://dx.doi.org/10.1037/a0035444

Nima, A. A., Rosenberg, P., Archer, T., \& Garcia, D. (2013). Anxiety, affect, self-esteem, and stress: mediation and moderation effects on depression. PLoS ONE, 8, e73265. http://dx.doi.org/10.1371/journal.pone.0073265

Norlander, T., Bood, S. Å., \& Archer, T. (2002). Performance during Stress: Affective Personality, Age and Regularity of Physical Exercise. Social Behavior and Personality, 30, 495-508. http://dx.doi.org/10.2224/sbp.2002.30.5.495

North, T. C., McCullagh, P., \& Tran, Z. V. (1990). Effect of Exercise on Depression. Exercise and Sport Sciences Reviews, 18, 379-416. http://dx.doi.org/10.1249/00003677-199001000-00016

Reed, J., \& Ones, D. S. (2006). The Effect of Acute Aerobic Exercise on Positive Activated Affect: A Meta-Analysis. Psychology of Sport and Exercise, 7, 477-514. http://dx.doi.org/10.1016/j.psychsport.2005.11.003

Rees, D. I., \& Sabia, J. J. (2010). Exercise and Adolescent Mental Health: New Evidence from Longitudinal Data. The Journal of Mental Health Policy and Economics, 13, 13-25.

Rosenberg, M., Schooler, C., Schoenbach, C., \& Rosenberg, F. (1995). Global Self-Esteem and Specific Self-Esteem: Different Concepts, Different Outcomes. American Sociological Review, 60, 141-156. http://dx.doi.org/10.2307/2096350

Rothon, C., Edwards, P., Bhui, K., Viner, R. M., Taylor, S., \& Stansfeld, S. A. (2010). Physical Activity and Depressive Symptoms in Adolescents: A Prospective Study. BMC Medicine, 8, 32. http://dx.doi.org/10.1186/1741-7015-8-32

Seligman, M., \& Csikszentmihalyi, M. (2000). Positive Psychology. An Introduction. American Psychologist, 55, 5-14. http://dx.doi.org/10.1037/0003-066X.55.1.5

Seligman, M., Steen, T. A., Park, N., \& Peterson, C. (2005). Positive Psychology Progress: Empirical Validation of Intervention. American Psychologist, 60, 410-421. http://dx.doi.org/10.1037/0003-066X.60.5.410

Stubbe, J., De Moor, M., Boomsma, D., \& De Geus, E. (2007). The Association between Exercise Participation and Well-Being: A Co-Twin Study. Preventive Medicine, 44, 148-152. http://dx.doi.org/10.1016/j.ypmed.2006.09.002

Thøgersen-Ntoumani, C., Fox, K. R., \& Ntoumanis, N. (2005). Relationships between Exercise and three Components of Mental Well-Being in Corporate Employees. Psychology of Sport and Exercise, 6, 609-627.

http://dx.doi.org/10.1016/j.psychsport.2004.12.004

Vuillemin, A., Boini, S., Bertrais, S., Tessier, S., Oppert, J. M., Hercberg, S. et al. (2005). Leisure Time Physical Activity and Health-Related Quality of Life. Preventive Medicine, 41, 562-569. http://dx.doi.org/10.1016/j.ypmed.2005.01.006 
Watson, D., \& Tellegen, A. (1985). Toward a Consensual Structure of Mood. Psychological Bulletin, 98, 219-235. http://dx.doi.org/10.1037/0033-2909.98.2.219

Watson, D., Clark, L. A., \& Tellegen, A. (1988). Development and Validation of Brief Measures of Positive and Negative Affect: The PANAS Scales. Journal of Personality and Social Psychology, 54, 1063-1070. http://dx.doi.org/10.1037/0022-3514.54.6.1063

Weisberg, Y. J., DeYoung, C. G., \& Hirsh, J. B. (2011). Gender Differences in Personality across the Ten Aspects of the Big Five. Frontiers in Psychology, 2, 178. http://dx.doi.org/10.3389/fpsyg.2011.00178 